\title{
The PI3K regulatory subunit gene PIK3R1 is under direct control of androgens and repressed in prostate cancer cells
}

\author{
Jennifer Munkley ${ }^{1}$, Karen E. Livermore ${ }^{1}$, Urszula L. McClurg², Gabriela \\ Kalna $^{3,4}$, Bridget Knight ${ }^{5}$ Paul McCullagh', John McGrath7, Malcolm \\ Crundwell $^{8}$, Hing Y. Leung ${ }^{3,4}$, Craig N. Robson ${ }^{2}$, Lorna W. Harries ${ }^{9}$ Prabhakar $^{2}$ \\ Rajan $^{3,4}$ and David J. Elliott ${ }^{1}$ \\ ${ }^{1}$ Institute of Genetic Medicine, Newcastle University, Newcastle-upon-Tyne, UK \\ ${ }^{2}$ Northern Institute for Cancer Research, Newcastle University, Newcastle-upon-Tyne, UK \\ ${ }^{3}$ Cancer Research UK Beatson Institute, Glasgow, UK \\ ${ }^{4}$ Institute of Cancer Sciences, University of Glasgow, Glasgow, UK \\ ${ }^{5}$ NIHR Exeter Clinical Research Facility, Royal Devon and Exeter NHS Foundation Trust, Exeter, UK \\ ${ }^{6}$ Department of Pathology, Royal Devon and Exeter NHS Foundation Trust, Exeter, UK \\ ${ }^{7}$ Exeter Surgical Health Services Research Unit, Royal Devon and Exeter NHS Foundation Trust, Exeter, UK \\ ${ }^{8}$ Department of Urology, Royal Devon and Exeter NHS Foundation Trust, Exeter, UK \\ ${ }^{9}$ Institute of Biomedical and Clinical Sciences, University of Exeter, Devon, UK \\ Correspondence to: Jennifer Munkley, email: jennifer.munkley@ncl.ac.uk \\ Keywords: PI3K signalling, PIK3R 1, p85a, androgens, prostate cancer
}

Received: August 18, $2015 \quad$ Accepted: September 12, $2015 \quad$ Published: September 14, 2015

This is an open-access article distributed under the terms of the Creative Commons Attribution License, which permits unrestricted use, distribution, and reproduction in any medium, provided the original author and source are credited.

\section{ABSTRACT}

Androgen receptor (AR) signalling and the PI3K pathway mediate survival signals in prostate cancer, and have been shown to regulate each other by reciprocal negative feedback, such that inhibition of one activates the other. Understanding the reciprocal regulation of these pathways is important for disease management as tumour cells can adapt and survive when either single pathway is inhibited pharmacologically. We recently carried out genome-wide exon-specific profiling of prostate cancer cells to identify novel androgen-regulated transcriptional events. Here we interrogated this dataset for novel androgen-regulated genes associated with the PI3K pathway. We find that the PI3K regulatory subunits PIK3R1 (p85a) and PIK3R3 (p55y) are direct targets of the AR which are rapidly repressed by androgens in LNCaP cells. Further characterisation revealed that the PIK3CA p110a catalytic subunit is also indirectly regulated by androgens at the protein level. We show that PIK3R1 mRNA is significantly under-expressed in prostate cancer ( $\mathrm{PCa}$ ) tissue, and provide data to suggest a context-dependent regulatory mechanism whereby repression of the p85a protein by the AR results in destabilisation of the PI3K p110a catalytic subunit and downstream PI3K pathway inhibition that functionally affects the properties of prostate cancer cells.

\section{INTRODUCTION}

Prostate cancer (PCa), the most commonlydiagnosed malignancy in males [1], is characterised by its dependence on androgen receptor (AR) signalling. The initial treatment standard for patients with locally advanced or metastatic $\mathrm{PCa}$ is androgen deprivation therapy (ADT). This usually inactivates the AR, but after 
2-3 years many patients develop castrate resistant $\mathrm{PCa}$ (CRPCa) where despite low serum testosterone levels AR signalling persists [2]. Progression to CRPCa may be the result of reactivation of AR signalling or reprogramming of the AR transcriptional landscape and has limited treatment options[3-5].

The phosphatidylinositol 3-kinase (PI3K) pathway is a key oncogenic signalling pathway in prostate cancer and has been shown to be altered in $42 \%$ of primary and up to $49 \%$ of metastatic cases[6, 7]. PIK3 signalling has a diverse array of functions including the regulation of cell survival, growth, proliferation, metabolism and angiogenesis [8]. The PI3K enzyme is an obligate heterodimer composed of a catalytic subunit (p110a) and one of a number of regulatory subunits [27]; the most common of which is derived from the $\mathrm{p} 85 \mathrm{a}$ gene (PIK3R1). Recently, reciprocal cross-talk between AR signalling and the PI3K pathway has been highlighted as a potential mechanism underlying CRPCa. AR signalling and the PI3K pathway have been shown to regulate each other by reciprocal negative feedback, such that inhibition of one pathway activates the other[9]. As both pathways mediate survival signals in prostate cancer tumour cells can adapt and survive when either single pathway is inhibited pharmacologically. Understanding the reciprocal regulation of these pathways is of critical importance in terms of disease management.

We recently carried out a global analysis of the PCa transcriptome to identify novel androgen-regulated transcriptional events[10-12]. In the light of evidence implicating cross-talk with the AR, we searched this dataset for novel androgen-regulated genes associated with PI3K signalling. Our data identifies a direct transcriptional link between the androgen receptor and PIK3 signalling pathways. We find that the PIK3RI gene is directly repressed by androgens and has decreased expression in clinical prostate cancer. Our data suggests a contextdependent regulatory mechanism whereby AR-mediated repression of the $\mathrm{p} 85 \mathrm{a}$ protein results in destabilisation of the PI3K p110a catalytic subunit and downstream PI3K pathway inhibition.

\section{RESULTS}

\section{The PI3K regulatory subunit genes $P I K 3 R 1$ and $P I K 3 R 3$ are direct targets of the AR}

Complete gene lists from our ExonArray dataset [10] were correlated with previously published mRNA expression data from 218 prostate tumours [6] with the aim of identifying novel androgen-regulated genes with roles in PI3K signalling. This highlighted two androgenregulated subunits of PI3K encoded for by the PIK3RI and PIK3R3 genes which were identified by Taylor et al.
(2010) as being inactivated in 58\% and $16 \%$ of metastatic prostate cancer tumours respectively [6] (Figure 1). Full gene lists were then uploaded to the web-based Ingenuity Pathway Analysis (IPA) software programme, and the IPA 'Core Analysis' function was used to identify additional androgen-regulated genes within pathways associated with PIK3R1 and PIK3R3 (Supplementary Figures $1 \& 2$ ). This identified an additional 34 genes which were validated as androgen-regulated in LNCaP cells by real-time PCR (Supplementary Table 1). The genomic loci of AR binding sites mapped by ChIP in LNCaP cells [13] were uploaded onto the UCSC genome browser. Two known AR binding sites within $100 \mathrm{~kb}$ of the $P I K 3 R 1$ gene and four AR binding sites within $50 \mathrm{~kb}$ of the $P I K 3 R 3$ gene were identified (Supplementary Table 2).

To test whether the PIK3R1 and PIK3R3 genes might be under direct control of androgens through AR regulation, we examined $P I K 3 R 1$ and PIK3R3 expression in LNCaP cells grown in steroid deplete medium and cells treated with $10 \mathrm{nM}$ of the synthetic androgen analogue R1881 for 24 hours by real-time PCR. The PIK3CA gene which codes for the p110a catalytic subunit of PI3K was also studied. PIK3RI and PIK3R3 mRNA expression were significantly reduced within 9 hours of treatment with 10nM R1881 $(\mathrm{p}<0.015)$, whereas there was no significant change in $P I K 3 C A$ expression (Figure 2A,B). Repression of the PIK3R1 and PIK3R3 genes was also observed with a range of $\mathrm{R} 1881$ concentrations from $1 \mathrm{nM}$ to $100 \mathrm{nM}(\mathrm{p}<0.01)$ consistent with this happening under physiological conditions within the prostate (Figure 2C). To test whether androgen-mediated suppression of $P I K 3 R 1$ and $P I K 3 R 3$ is a direct result of AR activity, we

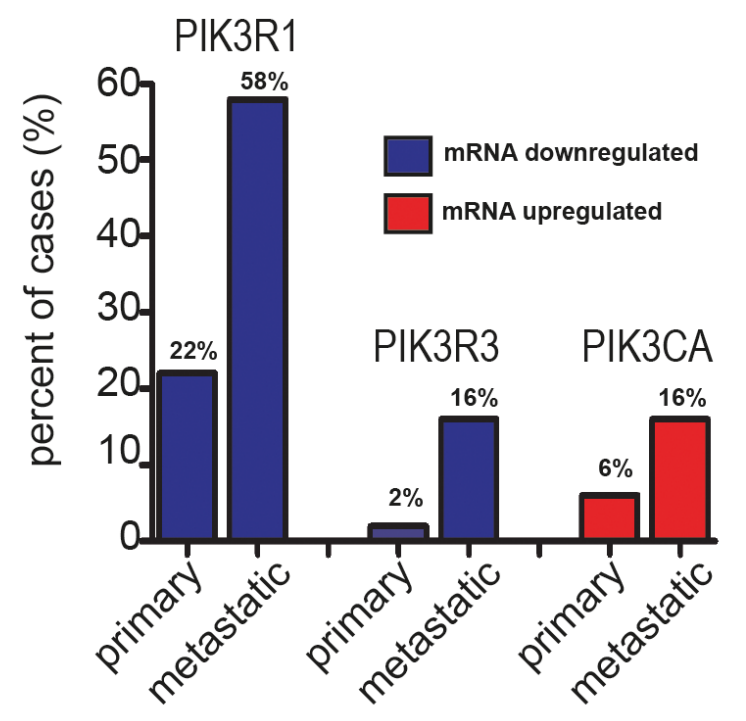

Figure 1: Expression of PIK3R1, PIK3R3 and PIK3CA mRNA in 218 prostate cancer clinical samples as measured by Taylor et al. [6]. PIK3R1 mRNA is downregulated in $22 \%$ of primary and $58 \%$ of metastatic prostate cancer tissue samples (relative to normal prostate tissue). 
treated LNCaP cells with 10nM R1881 in the presence and absence of cycloheximide to inhibit de novo protein synthesis. Androgen mediated down-regulation of PIK3RI and PIK3R3 was still observed in the presence of the protein synthesis inhibitor cycloheximide $(\mathrm{p}<0.04)$. Again, addition of cycloheximide had no effect on the expression of PIK3CA mRNA. The observation that PIK3RI and
PIK3R3 repression is not affected by inhibition of de novo protein synthesis indicates that this is likely to be directly mediated by the AR (Figure 2D). Although unlikely, it is still also possible that the regulation of $P I K 3 R 1$ and $P I K 3 R 3$ by androgens is mediated by an intermediate protein with a long half-life (which is the case for the AR).
A

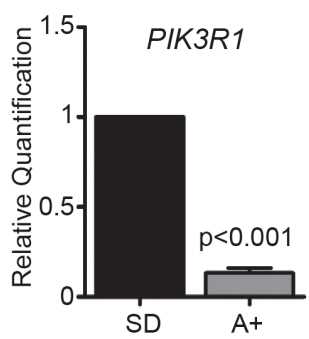

B

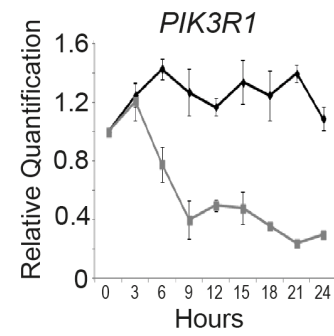

C

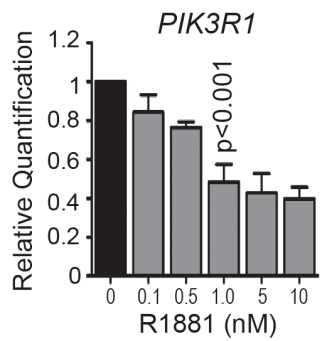

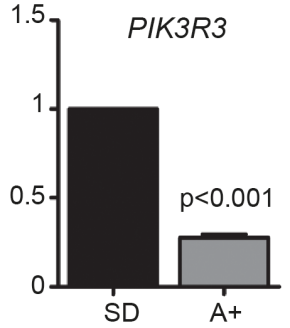

PIK3R3

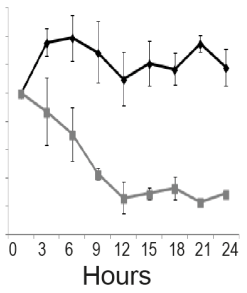

PIK3R3
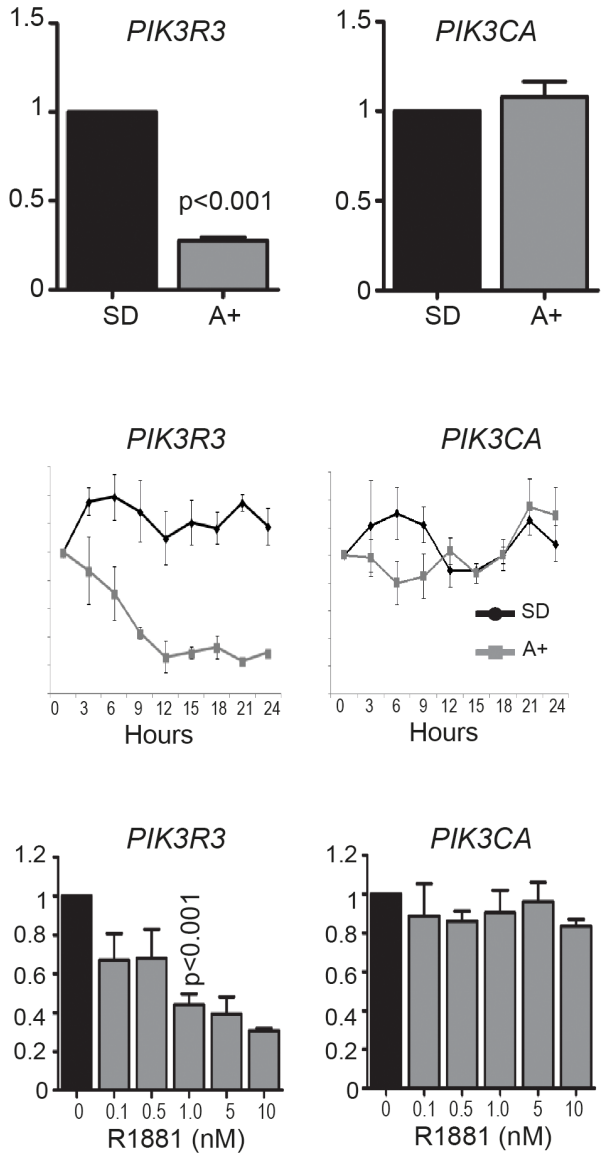

PIK3CA

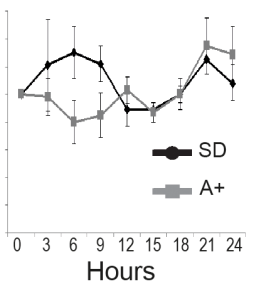

Hours

D
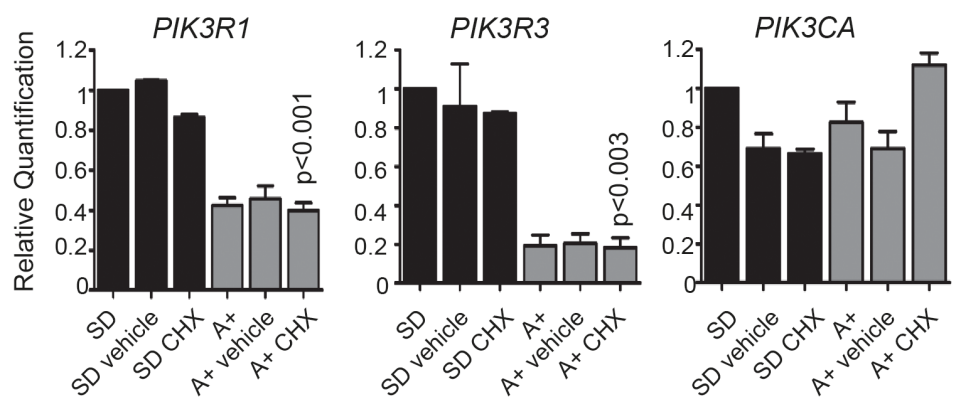

Figure 2: The PI3K regulatory subunit genes PIK3R1 and PIK3R3 are direct targets of the AR. (A) LNCaP cells were cultured in medium supplemented with $10 \%$ dextran charcoal stripped FBS to produce a steroid deplete medium (SD). Following culture for 72 hours, cells were treated with $10 \mathrm{nM}$ synthetic androgen analogue methyltrienolone (R1881) for 24 hours (A+). Relative expression of PIK3R1, PIK3R3 and PIK3CA was detected by real-time PCR (B) Expression of PIK3R1, PIK3R3 and PIK3CA mRNA in cells grown in steroid deplete $(\mathrm{SD})$ or androgen $(\mathrm{A}+)$ treated conditions over a 24 hours period. The response to androgens was confirmed using PSA (KLK3) expression (not shown). (C) Repression of PIK3R1 and PIK3R3 is also evident in LNCaP cells treated with 0.1 to $100 \mathrm{nM}$ of R1881. (D) The reduction in $P I K 3 R 1$ and $P I K 3 R 3$ mRNA expression in response to androgens is still seen in the presence of $1 \mu \mathrm{g} / \mathrm{ml}$ cycloheximide (CHX) as confirmed by real-time PCR. 


\section{The p85a, p55y and p110a proteins are repressed} by androgens

The above data shows that the p85a PI3K regulatory subunit gene $P I K 3 R 1$ and the $\mathrm{p} 55 \mathrm{y}$ subunit gene $P I K 3 R 3$ are direct transcriptional targets of the AR, whereas expression of the p110a PI3K catalytic subunit PIK3CA gene does not change with androgens. We next examined parallel expression of the p110a, p85a and $\mathrm{p} 55 \mathrm{y}$ proteins in $\mathrm{LNCaP}$ cells using western blotting and immunofluorescence. The expression of the p85a and $\mathrm{p} 55 \mathrm{y}$ proteins was repressed by treatment of $10 \mathrm{nM}$ R1881 for either 24 or 48 hours. Although we did not see any change in expression at the transcript level of the $P I K 3 C A$ gene in response to androgens in $\mathrm{LNCaP}$ cells, at the protein level p110a was strongly repressed after treatment with androgens (Figure 3A,B). Confirming this effect on protein levels was mediated by the AR, we found that androgen-mediated repression of the $\mathrm{p} 85 \mathrm{a}, \mathrm{p} 55 \mathrm{y}$ and $\mathrm{p} 110 \mathrm{a}$ proteins is prevented when cells are depleted of the AR using esiRNA (Figure 3C). The specificity of the antibodies used was confirmed by detection of over-expressed protein and detection of esiRNA mediated protein depletion (Figure 4A \& Supplementary Figures 3A,B). Taken together, these results indicate that while the PI3K regulatory subunits $\mathrm{p} 85 \mathrm{a}$ and $\mathrm{p} 55 \mathrm{y}$ are direct targets of the AR which are rapidly repressed by androgens, repression of the PI3K catalytic subunit p110a by androgens operates at the protein level only. Consistent with this pattern of repression of the PIK3 pathway, as observed previously [14] treatment of LNCaP cells with androgens also reduced expression levels of phosphorylated AKT (pAKT).

\section{The p110a PI3K catalytic subunit is stabilised by p85a}

The above data predicted that AR-regulated suppression of p85a, p55y and p110a in PCa cells may modulate PI3K signalling in response to androgens. To test this prediction, we depleted $\mathrm{p} 85 \mathrm{a}$ and $\mathrm{p} 55 \mathrm{y}$ using esiRNA and examined the downstream effects on PI3K signalling in LNCaP cells. The p85a regulatory subunit has previously been shown to regulate and stabilise the PIK3CA p110a catalytic protein [15-17] 35]. Consistent with this, knockdown of p85a caused a reduction in p110a protein levels (Figure 4A). This result was confirmed by over-expression of p85a in HEK293 cells (which increased the level of p110a) (Supplementary Figure 3A). These findings support the repression of p110a by androgens being mediated by a mechanism involving reduction of its protein partner p85a (which is a direct target of the AR). In contrast, both depletion of $\mathrm{p} 55 \mathrm{y}$ by esiRNA in LNCaP cells, and over-expression of p55y in HEK293 cells had no significant effect on p110a protein levels (Supplementary Figure 3A.B).
A

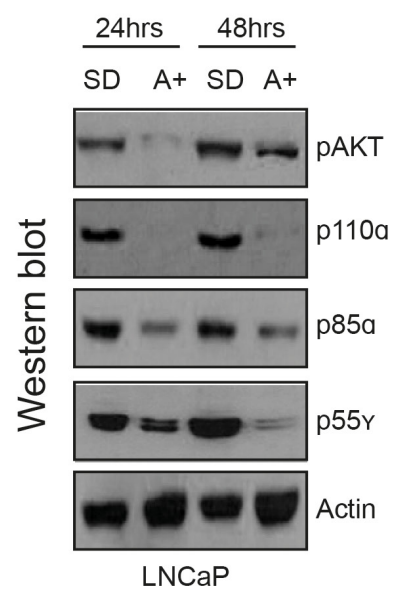

B
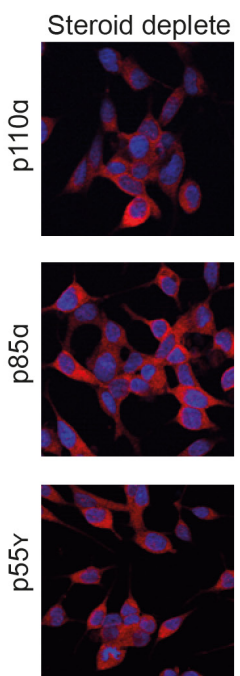

C
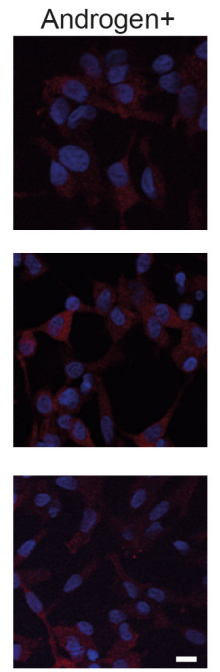

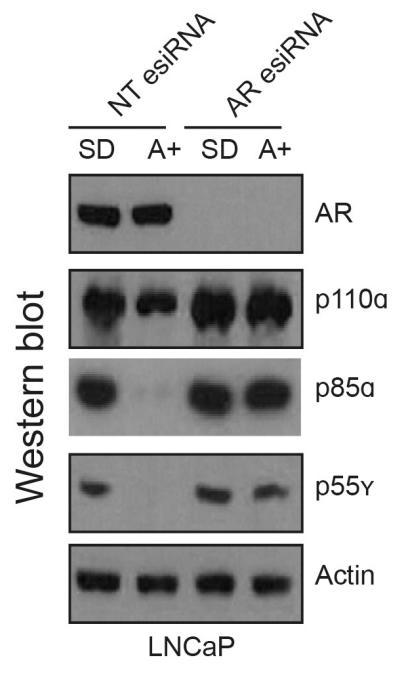

Figure 3: The p85a, p55y and p110a proteins are repressed by androgens. (A) Expression of p85a, p55y and p110a protein is reduced in LNCaP cells treated with $10 \mathrm{nM} \mathrm{R} 1881$ for 24 and 48 hours as detected by western blot. Actin was used as a loading control. (B) Immunofluorescent staining of LNCaP cells grown in steroid depleted conditions indicates that p85a, p55y and p110a are localised to the cytoplasm. Bar is $10 \mu \mathrm{M}$. (C) Depletion of AR protein in LNCaP cells by esiRNA shows that when the AR is depleted there is no reduction in $\mathrm{p} 85 \mathrm{a}, \mathrm{p} 55 \mathrm{y}$ or $\mathrm{p} 110 \mathrm{a}$ protein in response to androgens. The specificity of the antibodies used was confirmed by detection of over-expressed protein and esiRNA mediated protein depletion (Supplementary Figure 3). 


\section{Depletion of p85a reduces pAKT in LNCaP cells and decreases cell proliferation}

We next examined phosphorylation of the serine kinase AKT (pAKT) as an indicator of endogenous PI3K activity [18]. Depletion of p85a in LNCaP cells reduced levels of pAKT (actin and total AKT levels were used as loading controls). In contrast, depletion of p55y had no effect on pAKT. These results suggest that in LNCaP cells the depletion of $\mathrm{p} 85 \mathrm{a}$ but not $\mathrm{p} 55 \mathrm{y}$ reduces PI3K activity (Figure 4A and Supplementary Figure 3B). Activated AKT kinase modulates the function of numerous substrates involved in cell cycle progression $[19,20]$, and we observed that depletion of p85a in LNCaP cells led to reduced levels of cyclinD mRNA and protein (Figure 4A). Consistent with these changes, cell cycle analysis of PIK3R1 depleted cells indicated a significant reduction in the proportion of cells in $S$ phase $(p<0.01)$ and an increase in $\mathrm{G}_{0} / \mathrm{G}_{1}(\mathrm{P}<0.02)$ (Figure $4 \mathrm{~B}$ ). We also observed significantly reduced cell growth after treatment with PIK3R1 esiRNA ( $>0.03$ ) (Figure 4C). Taken together our results suggest that depletion of $\mathrm{p} 85 \mathrm{a}$ in $\mathrm{LNCaP}$ cells results in downstream PI3K pathway inhibition that can functionally affect the properties of prostate cancer cells. As depletion of PIK3R1 by esiRNA in LNCaP cells reduced expression of $C C N D 1$ mRNA we tested whether patients with reduced $P I K 3 R 1$ also have reduced cyclin $D$ expression. Consistent with this, re-analysis of the data generated by Taylor et al. [6] indicated a significant tendency towards co-occurance $(\mathrm{p}<0.007)$ for both downregulation of $P I K 3 R 1$ and cyclin $D$ (Figure 4D).

\section{PIK3R1 is under-expressed in PCa}

We carried out a further meta-analysis of 747 prostate cancer tumours using data from 10 previously published studies[6, 21-29]. Analysis of PIK3R1, PIK3R3 and $P I K 3 C A$ mRNA expression in these datasets revealed that $P I K 3 R 1$ was significantly down-regulated in $\mathrm{PCa}$ tumours relative to normal tissue in 9 of the 10 studies. PIK3R3 and PIK3CA were significantly altered in 3/10 studies and 1/10 respectively (Supplementary Table 3). Analysis of the 122 samples studied by Grasso et al. [23] identified PIK3R1 as -1.428 fold under-expressed
A

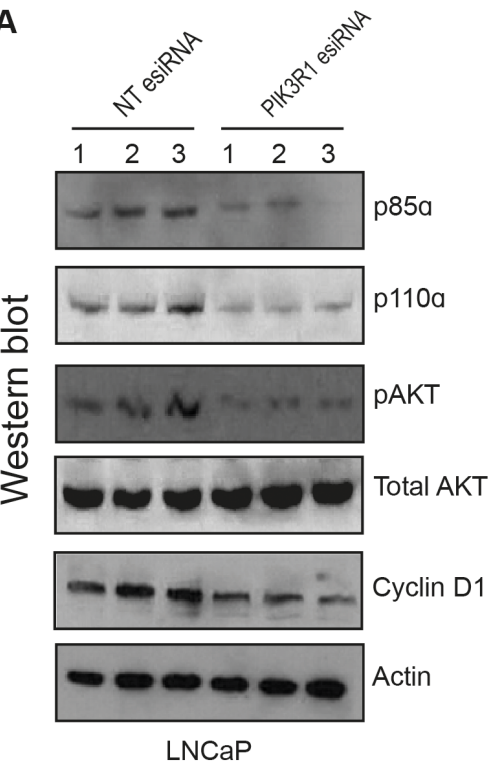

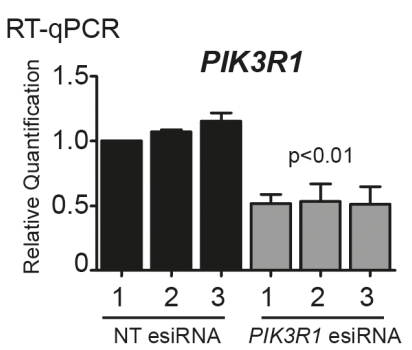

RT-qPCR

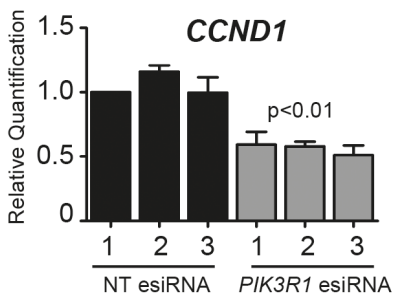

B

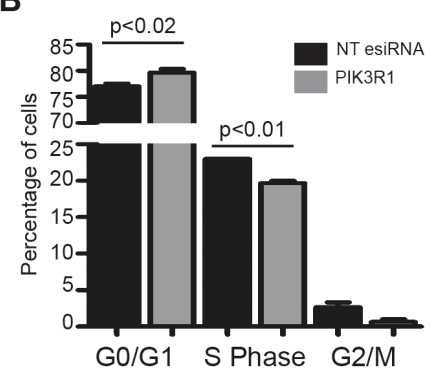

C

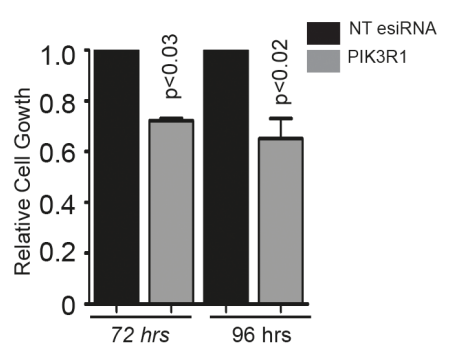

D

Tendency towards co-occurrence: significant $(p<0.007)$

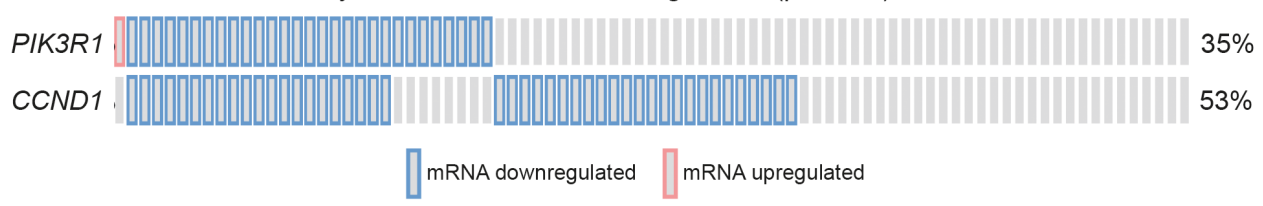

Figure 4: Depletion of p85a reduces pAKT in LNCaP cells and decreases cell proliferation. (A) Depletion of $P I K 3 R 1$ / p85a in LNCaP cells by esiRNA was confirmed by western blotting (left panel) and by real-time PCR (right panel). Loss of p85a caused a reduction in the relative levels of p110a, pAKT (total AKT and actin were used as loading controls), and cyclin D. (B) Cell cycle analysis of LNCaP cells treated with PIK3RI esiRNA for 72 hours. (C) Relative cell number counts for LNCaP cells treated with PIK3RI esiRNA for 72 or 96 hours. (D) Analysis of data generated by Taylor et al. [6] for co-occurrence of PIK3R1 and CCND1 mRNA under-expression. 
in prostate carcinoma relative to normal prostate tissue ( $\mathrm{p}=4.99 \mathrm{E}-5)$ and placed PIK3R1 in the top $10 \%$ of under-expressed genes (Figure 5A). Similarly, analysis of 101 samples studied by Tomlins et al. [21] found that expression of PIK3R1 was reduced by -3.266 fold $(\mathrm{p}=5.87 \mathrm{E}-7)$ in prostate carcinoma relative to normal tissue, and in this dataset PIK3RI was in the top $1 \%$ of under-expressed genes (Figure 5B) (data was generated using Oncomine [30]). Interrogation of previously

A

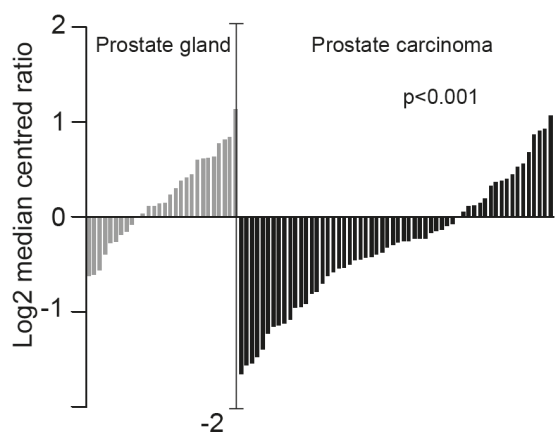

C

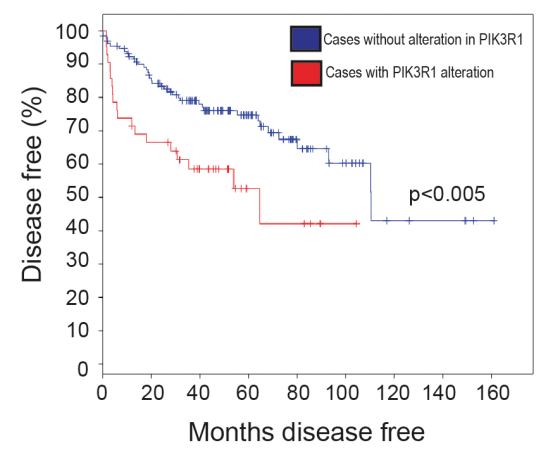

published data [6] also showed reduced survival in patients where the $P I K 3 R 1$ gene is altered (median months disease free is reduced from 110 to $65(\mathrm{p}<0.005)$ (Figure 5C). We also analysed expression of PIK3R1 mRNA in 9 prostate tumour tissue samples relative to matched normal tissue from the same patient. PIK3R 1 expression was significantly reduced in $6 / 9$ prostate tumour tissue samples when compared with matched normal tissue from the same patient (Figure 5D). Analysis of PIK3R3
B

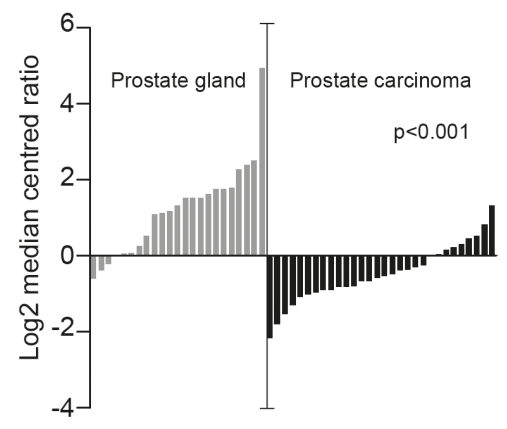

D

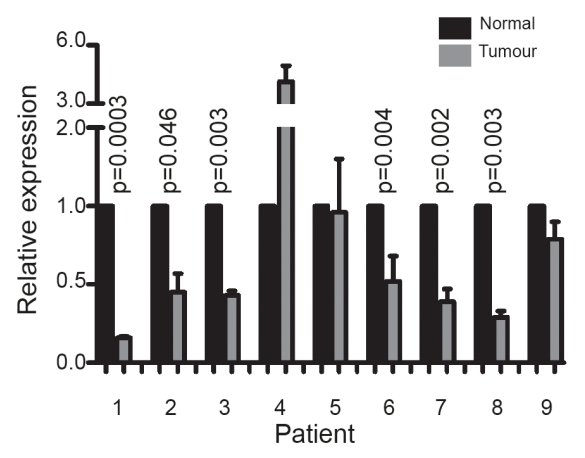

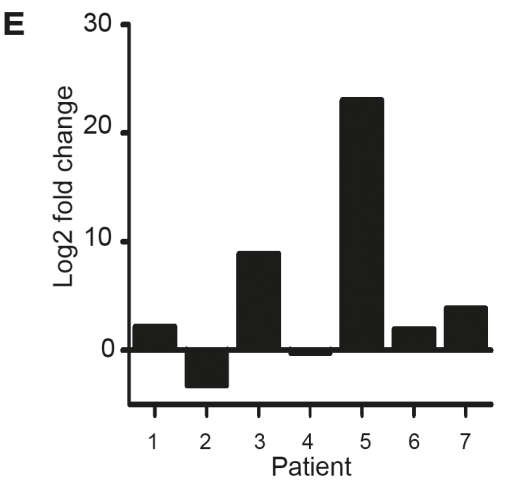

Figure 5: PIK3R1 is under-expressed in PCa. Expression of PIK3R1 in clinical PCa samples measured by (A) Grasso et al. [23] and (B) Tomlins et al. [21]. In both studies the expression of PIK3R1 mRNA is significantly reduced in prostate carcinoma relative to normal prostate gland tissue. Data was generated using Oncomine [30]. (C) Interrogation of previously published data [6] also showed a reduced rate of survival in patients which have an alteration in the PIK3R1 gene. (D) Real-time PCR analysis of PIK3R1 mRNA expression in matched normal and tumour tissue from 9 PCa patients. Expression of PIK3R1 was significantly reduced in tumour relative to normal tissue in 6 out of the 9 patients studied $(\mathrm{p}<0.05)$. (E) Analysis of PIK3RI mRNA in previously published RNA-sequencing data [33] from 7 prostate cancer patients before and after androgen ablation therapy. PIK3R1 expression is increased in 5/7 patients following the removal of androgens (measured by $\log 2$ fold change of RNA-Seq reads detected). 
and PIK3CA expression in the same sample sets indicated no significant differences (Supplementary Figure 4). The above data indicates that PIK3R1 expression is repressed by the androgen receptor in $\mathrm{LNCaP}$ cells in response to androgens. In order to see if reciprocal changes might occur in patients before and after androgen deprivation therapy we analysed previously published RNASequencing data from $7 \mathrm{PCa}$ patients [13]. In 5/7 patients expression of $P I K 3 R 1$ was increased after androgens were depleted (Figure 5E) consistent with the change in PIK3R1 expression in response to androgens being increased in patients in response to anti-androgen treatment. Taken together, these results indicate that PIK3R1 is underexpressed in $\mathrm{PCa}$.

\section{DISCUSSION}

Here we show that expression of the PI3K regulatory subunit $\mathrm{p} 85 \alpha$ protein-encoding gene PIK3RI is under direct control of androgens and is reduced in prostate carcinoma tissue relative to the normal prostate gland. Our data identifies a direct transcriptional link between the androgen receptor and PI3K signalling pathways and suggests a context-dependent regulatory mechanism whereby repression of the $\mathrm{p} 85 \alpha$ protein by the

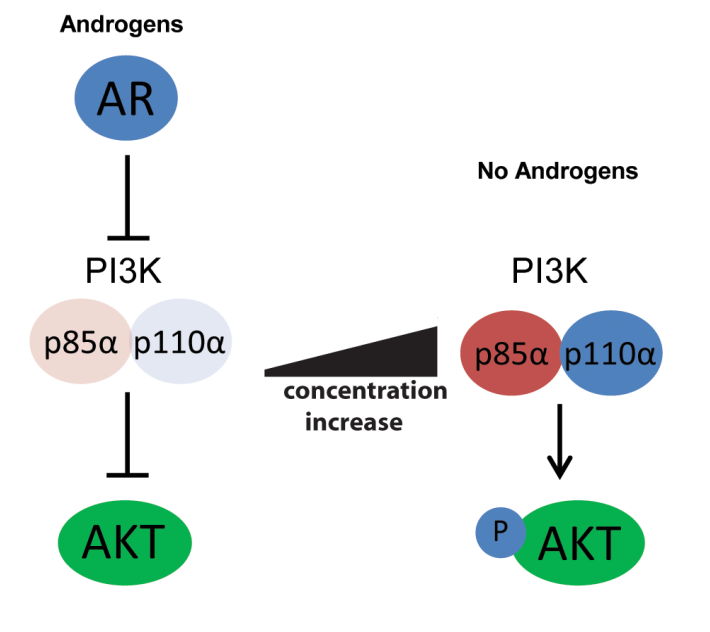

PI3K pathway inhibition

PI3K pathway activation

Figure 6: Model: AR-mediated repression of the p85a protein results in destabilisation of the PI3K p110a catalytic subunit and downstream PI3K pathway inhibition. Androgen receptor (AR) signalling and the PI3K pathway have been shown to regulate each other by reciprocal negative feedback in PTEN negative cells. We show that the PI3K regulatory subunit PIK3RI (p85a) is a direct target of the AR which is rapidly repressed by androgens in prostate cancer cells. The data presented suggests a context-dependent regulatory mechanism whereby repression of the $\mathrm{p} 85 \mathrm{a}$ protein by the AR results in destabilisation of the PI3K p110a catalytic subunit downstream PI3K pathway inhibition.
AR results in destabilisation of the PI3K p $110 \alpha$ catalytic subunit and downstream PI3K pathway inhibition (Figure 6). A reciprocal regulation between PI $3 K$ and AR and signalling pathways has been previously implicated in prostate tumorigenesis [7][14, 33]. As tumour cells can adapt and survive when either single pathway is inhibited pharmacologically, understanding the reciprocal regulation of these pathways further is crucial for disease management [31]. Carver et al. [7] showed that PI3K signalling inhibits AR signalling via feedback inhibition of human epidermal growth factor $2 / 3$ (HER2/3), and that AR signalling down-regulates $\mathrm{PI} 3 \mathrm{~K}$ signalling through FK506-binding protein-5 (FKBP-5) mediated stabilisation of the AKT phosphatase PHLPP [7]. The new data reported here thus indicate that these two pathways are even more closely linked at the level of transcriptional control.

PIK3R1 under-expression has previously been shown to be an independent prognostic marker in breast cancer [29] and low PIK3R1 expression has been linked to high grade lung cancer [30]. Liver specific loss of PIK3RI in a murine model results in the development of aggressive hepatocellular cancer [13], and loss of PIK3R1 mRNA in the MCF- 7 breast cancer cell line is associated with a more invasive phenotype [32]. Studies have also suggested that PIK3R1 expression negatively influences glioblastoma tumour growth and patient survival [33]. The role of $\mathrm{p} 85 \alpha$ in the PI3K pathway is complex. In contrast to the studies discussed above, PIK3R1 has also been implicated as an oncogene in endometrial, ovarian and colon tumours [28] [16]. Previous studies have shown that optimal signalling through the PIK3 pathway depends on a critical molecular balance between the regulatory and catalytic subunits; haploinsufficiency of PIK3R1 can result in PI3K pathway activation, whereas homozygous depletion inhibits the pathway [22][31, 34]. Point mutations in and deletions of the PIK $3 R 1$ gene have been reported in up to $20 \%$ of endometrial cancer cases and in $2.2 \%$ of breast cancers $[16,36][29]$. Analysis of organoid cultures derived from patients with advanced prostate cancer detected mutations in PIK3R1 in 2/7 patients [30]. Taylor et al. [6] did not identify any PIK3RI mutations in their study of $218 \mathrm{PCa}$ tumours. However, a recent study by Robinson et al. [7] identified PIK3R1 mutations and deletions in $4.7 \%$ and $1.3 \%$ of metastatic CRPCa respectively. Together with our data this shows that down-regulation of PIK3R1 mRNA/ $\mathrm{p} 85 \alpha$ is more common in prostate tumours than mutation of the gene, and the effect of p $85 \alpha$ on the PI3K pathway and tumour development is likely to be tissue and contextdependent and determined by the relative activities of $\mathrm{p} 110 \alpha, \mathrm{p} 85 \alpha$ and PTEN.

Our work demonstrates a direct transcriptional link between AR signalling and the PI3K pathway mediated by AR-dependent repression of PIK3R1. Recent work has demonstrated a dynamic interplay between PI3K and AR 
signalling in resistance to ADT [31, 32]. Activation of PI3K signalling as a result of treatments targeting the AR may therefore enable prostate cancer cells to survive and proliferate without androgens. This concept is underlined by the finding that androgen inhibition actually accelerates progression to invasive $\mathrm{PCa}$ in PTEN-deficient mice [34]. These findings and the work described in this study support a route involving combinatorial inhibition of AR and $\mathrm{PI} 3 \mathrm{~K}$ signalling to significantly reduce progression to CRPCa [35].

\section{METHODS}

\section{IPA pathway analysis}

Gene lists from Rajan et al. [10] were uploaded to the web-based Ingenuity Pathway Analysis (IPA; Ingenuity Systems) software programme, and the "Core Analysis" function was used to study direct and indirect regulatory relationships between genes and their known biological functions.

\section{Antibodies}

The following antibodies were used in the study: p85a mouse antibody (Abcam, ab22653), anti p55y rabbit antibody (Sigma, HPA005751), p110a rabbit antibody (Cell Signalling, 4249), Total AKT rabbit antibody (Santa Cruz, sc-8312), anti-phospho-AKT1 (pSer $\left.{ }^{473}\right)$ rabbit antibody (Sigma, SAB4300042), anti-Cyclin D1 (Abcam ab21699), anti-AR mouse antibody (BD Bioscience, 554226), anti-FLAG mouse monoclonal (F3165, Sigma), normal rabbit IgG (711-035-152 Jackson labs) and normal mouse IgG (715-036-150 Jackson labs).

\section{RT-qPCR}

Cells were harvested and total RNA extracted using TRI-reagent (Invitrogen, 15596-026), according to the manufacturer's instructions. RNA was treated with DNase 1 (Ambion) and cDNA was generated by reverse transcription of 500ng of total RNA using the Superscript VILO cDNA synthesis kit (Invitrogen, 11754-050). Quantitative PCR (qPCR) was performed in triplicate on cDNA using SYBR ${ }^{\circledR}$ Green PCR Master Mix (Invitrogen, 4309155) using the QuantStudio ${ }^{\text {TM }} 7$ Flex Real-Time PCR System (Life Technologies). Samples were normalised using the average of three reference genes: GAPDH, $\beta$-tubulin and actin. All primer sequences are listed in Supplementary Table 4.

\section{DNA constructs}

For creation of the Flp-In ${ }^{\mathrm{TM}}-293$ stable cell line PIK3R1 and PIK3CA and were cloned into pCDNA5 using BamH1 and Not1. PIK3R3 was cloned into pCDNA5 using Not 1 and Xho1.

\section{Cell culture}

Cell culture and androgen treatment of cells was as described previously [10-12]. All cells were grown at $37^{\circ} \mathrm{C}$ in $5 \% \mathrm{CO} 2 . \mathrm{LNCaP}$ cells (CRL-1740, ATCC) were maintained in RPMI-1640 with L-Glutamine (PAA Laboratories, R15-802) supplemented with 10\% Fetal Bovine Serum (FBS) (PAA Laboratories, A15101). For androgen treatment of LNCaP cells, medium was supplemented with $10 \%$ dextran charcoal stripped FBS (PAA Laboratories, A15-119) to produce a steroiddeplete medium. Following culture for 72 hours, 10nM synthetic androgen analogue methyltrienolone (R1881) (Perkin-Elmer, NLP005005MG) was added (Androgen + ) or absent (Steroid deplete) for the times indicated. Where indicated, LNCaP cells were pre-treated for 1 hour with vehicle (dimethylsulfoxide; DMSO) (Sigma, C1988) or $1 \mu \mathrm{g} / \mathrm{ml}$ cycloheximide (Sigma, D2438) prior to addition of $10 \mathrm{nM} \mathrm{R} 1881$ for 24 hours as previously described [16]. Flp-In ${ }^{\text {TM}}-293$ cells (R750-07, Invitrogen) were maintained in DMEM GlutaMax (Invitrogen, 10566040), supplemented with 10\% FBS (PAA Laboratories, A15-101) and stable cell lines generated using the FlpIn T-Rex Core Kit (K6500-01, Invitrogen) according to the manufacturer's instructions. Protein expression was induced using $1 \mu \mathrm{g} / \mathrm{ml}$ tetracycline (T7660, Sigma) for 72 hours.

\section{esiRNA}

esiRNAs PIK3R1 and PIK3R3 were obtained from Sigma-Aldrich (EHU151811 and EHU123491).

\section{Cell cycle analysis}

Cell cycle analysis was carried out using the $\mathrm{Tali}^{\mathrm{R}}$ Cell Cycle Kit (Life Technologies A10798) and the Tali ${ }^{\mathrm{R}}$ Image-based Cytometer. The data was then analysed using ModFit. Relative cell numbers following esiRNA treatment were determined using the Tali ${ }^{\mathrm{R}}$ Image-based Cytometer (Life Technologies).

\section{Clinical samples}

Our study made use of RNA from 32 benign samples from patients with benign prostatic hyperplasia $(\mathrm{BPH})$ and 
17 malignant samples from transurethral resection of the prostate (TURP) samples. Malignant status and Gleason score were obtained for these patients by histological analysis. We also analysed normal and matched PCa tissue from 9 patients obtained by radical prostectomy. The samples were obtained with ethical approval through the Exeter NIHR Clinical Research Facility tissue bank (Ref: STB20). Written informed consent for the use of surgically obtained tissue was provided by all patients.

\section{ACKNOWLEDGEMENTS}

This work was funded by Prostate Cancer UK, the J. G. W Patterson Foundation, Cancer Research UK (C9380/A15574) and the Wellcome Trust (grant numbers WT080368MA and WT089225/Z/09/Z) and BBSRC (grant BB/1006923/1). The authors would like to thank Exeter NIHR Clinical Research Facility, and Mr Ben Lee for technical assistance.

\section{CONFLICTS OF INTEREST}

The authors declare no competing financial interests.

\section{REFERENCES}

1. Center MM, Jemal A, Lortet-Tieulent J, Ward E, Ferlay J, Brawley $\mathrm{O}$ and Bray $\mathrm{F}$. International variation in prostate cancer incidence and mortality rates. Eur Urol. 2012; 61(6):1079-1092.

2. Karantanos T, Corn PG and Thompson TC. Prostate cancer progression after androgen deprivation therapy: mechanisms of castrate resistance and novel therapeutic approaches. Oncogene. 2013; 32(49):5501-5511.

3. Zong Y and Goldstein AS. Adaptation or selection-mechanisms of castration-resistant prostate cancer. Nat Rev Urol. 2013; 10(2):90-98.

4. Sharma NL, Massie CE, Ramos-Montoya A, Zecchini V, Scott HE, Lamb AD, MacArthur S, Stark R, Warren AY, Mills IG and Neal DE. The androgen receptor induces a distinct transcriptional program in castration-resistant prostate cancer in man. Cancer Cell. 2013; 23(1):35-47.

5. Feldman BJ and Feldman D. The development of androgenindependent prostate cancer. Nat Rev Cancer. 2001; 1(1):34-45.

6. Taylor BS, Schultz N, Hieronymus H, Gopalan A, Xiao Y, Carver BS, Arora VK, Kaushik P, Cerami E, Reva B, Antipin Y, Mitsiades N, Landers T, Dolgalev I, Major JE, Wilson $\mathrm{M}$, et al. Integrative genomic profiling of human prostate cancer. Cancer Cell. 2010; 18(1):11-22.

7. Robinson D, Van Allen EM, Wu YM, Schultz N, Lonigro RJ, Mosquera JM, Montgomery B, Taplin ME, Pritchard CC, Attard G, Beltran H, Abida W, Bradley RK, Vinson J, Cao X, Vats P, et al. Integrative clinical genomics of advanced prostate cancer. Cell. 2015; 161(5):1215-1228.
8. Bitting RL and Armstrong AJ. Targeting the PI3K/Akt/ mTOR pathway in castration-resistant prostate cancer. Endocr Relat Cancer. 2013; 20(3):R83-99.

9. Carver BS, Chapinski C, Wongvipat J, Hieronymus H, Chen Y, Chandarlapaty S, Arora VK, Le C, Koutcher J, Scher H, Scardino PT, Rosen N and Sawyers CL. Reciprocal feedback regulation of $\mathrm{PI} 3 \mathrm{~K}$ and androgen receptor signaling in PTEN-deficient prostate cancer. Cancer Cell. 2011; 19(5):575-586.

10. Rajan P, Dalgliesh C, Carling PJ, Buist T, Zhang C, Grellscheid SN, Armstrong K, Stockley J, Simillion C, Gaughan L, Kalna G, Zhang MQ, Robson CN, Leung HY and Elliott DJ. Identification of novel androgen-regulated pathways and mRNA isoforms through genome-wide exonspecific profiling of the LNCaP transcriptome. PLoS One. 2011; 6(12):e29088.

11. Munkley J, Rajan P, Lafferty NP, Dalgliesh C, Jackson RM, Robson CN, Leung HY and Elliott DJ. A novel androgenregulated isoform of the TSC2 tumour suppressor gene increases cell proliferation. Oncotarget. 2014; 5(1):131-139.

12. Munkley J, Lafferty NP, Kalna G, Robson CN, Leung HY, Rajan P and Elliott DJ. Androgen-regulation of the protein tyrosine phosphatase PTPRR activates ERK1/2 signalling in prostate cancer cells. BMC Cancer. 2015; 15(1):9.

13. Massie CE, Lynch A, Ramos-Montoya A, Boren J, Stark R, Fazli L, Warren A, Scott H, Madhu B, Sharma N, Bon H, Zecchini V, Smith DM, Denicola GM, Mathews N, Osborne $\mathrm{M}$, et al. The androgen receptor fuels prostate cancer by regulating central metabolism and biosynthesis. EMBO J. 2011; 30(13):2719-2733.

14. Lee SH, Johnson D, Luong R and Sun Z. Crosstalking between androgen and PI3K/AKT signaling pathways in prostate cancer cells. J Biol Chem. 2015; 290(5):27592768.

15. Shekar SC, Wu H, Fu Z, Yip SC, Nagajyothi, Cahill SM, Girvin ME and Backer JM. Mechanism of constitutive phosphoinositide 3-kinase activation by oncogenic mutants of the p 85 regulatory subunit. J Biol Chem. 2005; 280(30):27850-27855.

16. Taniguchi CM, Winnay J, Kondo T, Bronson RT, Guimaraes AR, Aleman JO, Luo J, Stephanopoulos G, Weissleder R, Cantley LC and Kahn CR. The phosphoinositide 3-kinase regulatory subunit p85alpha can exert tumor suppressor properties through negative regulation of growth factor signaling. Cancer Res. 2010; 70(13):5305-5315.

17. Sun M, Hillmann P, Hofmann BT, Hart JR and Vogt PK. Cancer-derived mutations in the regulatory subunit p85alpha of phosphoinositide 3-kinase function through the catalytic subunit p110alpha. Proc Natl Acad Sci U S A. 2010; 107(35):15547-15552.

18. Vanhaesebroeck B and Alessi DR. The PI3K-PDK1 connection: more than just a road to PKB. Biochem J. 2000; 346 Pt 3:561-576.

19. Chang F, Lee JT, Navolanic PM, Steelman LS, Shelton JG, 
Blalock WL, Franklin RA and McCubrey JA. Involvement of PI3K/Akt pathway in cell cycle progression, apoptosis, and neoplastic transformation: a target for cancer chemotherapy. Leukemia. 2003; 17(3):590-603.

20. Liang J and Slingerland JM. Multiple roles of the PI3K/ PKB (Akt) pathway in cell cycle progression. Cell Cycle. 2003; 2(4):339-345.

21. Tomlins SA, Mehra R, Rhodes DR, Cao X, Wang L, Dhanasekaran SM, Kalyana-Sundaram S, Wei JT, Rubin MA, Pienta KJ, Shah RB and Chinnaiyan AM. Integrative molecular concept modeling of prostate cancer progression. Nat Genet. 2007; 39(1):41-51.

22. Lapointe J, Li C, Higgins JP, van de Rijn M, Bair E, Montgomery K, Ferrari M, Egevad L, Rayford W, Bergerheim U, Ekman P, DeMarzo AM, Tibshirani R, Botstein D, Brown PO, Brooks JD, et al. Gene expression profiling identifies clinically relevant subtypes of prostate cancer. Proc Natl Acad Sci U S A. 2004; 101(3):811-816.

23. Grasso CS, Wu YM, Robinson DR, Cao X, Dhanasekaran SM, Khan AP, Quist MJ, Jing X, Lonigro RJ, Brenner JC, Asangani IA, Ateeq B, Chun SY, Siddiqui J, Sam L, Anstett $\mathrm{M}$, et al. The mutational landscape of lethal castrationresistant prostate cancer. Nature. 2012; 487(7406):239-243.

24. Luo J, Sobkiw CL, Logsdon NM, Watt JM, Signoretti S, O’Connell F, Shin E, Shim Y, Pao L, Neel BG, Depinho RA, Loda M and Cantley LC. Modulation of epithelial neoplasia and lymphoid hyperplasia in PTEN+/- mice by the $\mathrm{p} 85$ regulatory subunits of phosphoinositide 3-kinase. Proc Natl Acad Sci U S A. 2005; 102(29):10238-10243.

25. Arredouani MS, Lu B, Bhasin M, Eljanne M, Yue W, Mosquera JM, Bubley GJ, Li V, Rubin MA, Libermann TA and Sanda MG. Identification of the transcription factor single-minded homologue 2 as a potential biomarker and immunotherapy target in prostate cancer. Clin Cancer Res. 2009; 15(18):5794-5802.

26. Vanaja DK, Cheville JC, Iturria SJ and Young CY. Transcriptional silencing of zinc finger protein 185 identified by expression profiling is associated with prostate cancer progression. Cancer Res. 2003; 63(14):3877-3882.

27. Magee JA, Araki T, Patil S, Ehrig T, True L, Humphrey PA, Catalona WJ, Watson MA and Milbrandt J. Expression profiling reveals hepsin overexpression in prostate cancer. Cancer Res. 2001; 61(15):5692-5696.

28. Singh D, Febbo PG, Ross K, Jackson DG, Manola J, Ladd C, Tamayo P, Renshaw AA, D’Amico AV, Richie JP, Lander ES, Loda M, Kantoff PW, Golub TR and Sellers WR. Gene expression correlates of clinical prostate cancer behavior. Cancer Cell. 2002; 1(2):203-209.

29. Varambally S, Yu J, Laxman B, Rhodes DR, Mehra R, Tomlins SA, Shah RB, Chandran U, Monzon FA, Becich MJ, Wei JT, Pienta KJ, Ghosh D, Rubin MA and Chinnaiyan AM. Integrative genomic and proteomic analysis of prostate cancer reveals signatures of metastatic progression. Cancer Cell. 2005; 8(5):393-406.

30. Gao D, Vela I, Sboner A, Iaquinta PJ, Karthaus WR, Gopalan A, Dowling C, Wanjala JN, Undvall EA, Arora VK, Wongvipat J, Kossai M, Ramazanoglu S, Barboza LP, Di W, Cao Z, et al. Organoid cultures derived from patients with advanced prostate cancer. Cell. 2014; 159(1):176-187.

31. Wang S, Gao J, Lei Q, Rozengurt N, Pritchard C, Jiao J, Thomas GV, Li G, Roy-Burman P, Nelson PS, Liu X and $\mathrm{Wu}$ H. Prostate-specific deletion of the murine Pten tumor suppressor gene leads to metastatic prostate cancer. Cancer Cell. 2003; 4(3):209-221.

32. Jiao J, Wang S, Qiao R, Vivanco I, Watson PA, Sawyers $\mathrm{CL}$ and $\mathrm{Wu} \mathrm{H}$. Murine cell lines derived from Pten null prostate cancer show the critical role of PTEN in hormone refractory prostate cancer development. Cancer Res. 2007; 67(13):6083-6091.

33. Rajan P, Sudbery IM, Villasevil ME, Mui E, Fleming J, Davis M, Ahmad I, Edwards J, Sansom OJ, Sims D, Ponting CP, Heger A, McMenemin RM, Pedley ID and Leung HY. Next-generation sequencing of advanced prostate cancer treated with androgen-deprivation therapy. Eur Urol. 2014; 66(1):32-39. 